\title{
HLA DR antigens and gold toxicity
}

\author{
JAN TORE GRAN, GUNNAR HUSBY, AND ERIK THORSBY \\ From the Department of Rheumatology, Institute of Clinical Medicine, University of Troms $\emptyset$, Troms $\emptyset$, Norway, \\ and the Tissue Typing Laboratory, the National Hospital, Oslo, Norway
}

SUMMARY One hundred and thirty-two patients with rheumatoid arthritis treated with gold have been studied for possible associations between HLA DR antigens and different adverse reactions occurring during such therapy. Patients possessing HLA DR3 had a significantly greater frequency of side effects than patients lacking this antigen. It was particularly noticed that DR3 positive patients on gold treatment had an 11 times higher risk of getting proteinuria than those without DR3. The lowest frequency of side effects was seen in DR7 positives. No significant differences between the DR antigen groups with respect to skin eruptions, liver reactions, or leucopenia were evident.

Credit for the introduction of gold into the treatment of rheumatoid arthritis (RA) has been given to Forestier, ${ }^{1}$ but its favourable effect was first reported by Lande in $1927 .{ }^{2}$ But its use in the management of RA is limited by frequent and sometimes severe adverse reactions. It has been difficult to determine the factors predisposing to such reactions. ${ }^{3}$

During the last few years, however, it has been suggested that genetic markers such as HLA antigens might be of importance in predicting toxic reactions to gold. ${ }^{4}$ A genetic predisposition to gold toxicity was first suggested by Panayi et al., ${ }^{4}$ and these workers later showed that especially the development of proteinuria might be associated with the presence of certain HLA antigens. ${ }^{5}$ They showed that 19 out of 24 patients developing proteinuria during aurothiomalate or D-penicillamine therapy carried HLA B8 and HLA DR3. ${ }^{4-6}$ The same authors ${ }^{6}$ noted a marked trend for more severe and sudden haematological disorders to occur in patients with DR3. They also suggested a negative correlation between DR4 and proteinuria induced by these drugs, and an association between the development of mouth ulceration and the presence of DR2. Other workers ${ }^{7}$ have proposed that DR7 has a protective effect, as fewer patients with this antigen developed side effect than those without it.

After having experienced a high frequency of adverse reactions to aurothiomalate in our RA patients, we looked for associations between HLA DR antigens and some of the commonest of these reactions during treatment.

Accepted for publication 10 June 1982.

Correspondence to J. T. Gran, MD, Department of Rheumatology, University Hospital of Troms $\varnothing, 9000$ Troms $\varnothing$, Norway.

\section{Materials and methods}

Patients. One hundred and sixty RA patients admitted to the Troms $\varnothing$ Regional University Hospital have been tissue typed, and 132 of them, 96 females and 36 males, received treatment with parenteral gold. All the patients met at least 5 of the American Rheumatism Association criteria ${ }^{8}$ for RA. One hundred and twenty-two of them had classical erosive RA, while 10 patients had definite RA but lacked characteristic $x$-ray evidence of the disease. The age of the patients when gold therapy was started ranged from 25 to 72 years, with a mean of 53 years, and the mean duration of disease was $5 \cdot 3$ years (range $0 \cdot 5-30$ years). The Waaler-Rose test was used for determination of rheumatoid factor, and a titre of 1 in 32 or more was regarded as positive. One hundred and twenty-four patients were seropositive, while 8 patients gave negative results when repeatedly tested for RF.

Gold. Gold was in all instances given intramuscularly as sodium aurothiomalate (Myocrisin). A standard regimen consisted of one initial injection of 10 $\mathrm{mg}$ followed by $20 \mathrm{mg}$ in two doses and then weekly doses of $50 \mathrm{mg}$. After a total dose of $1000 \mathrm{mg}$ had been reached, $50 \mathrm{mg}$ of gold was given monthly as long as the therapy was considered beneficial to the patient. Only those patients who received $1000 \mathrm{mg}$ or more or developed toxic reactions were included in the present series.

Adverse reactions. No attempts were made at distinguishing between the different rashes that occurred, and the patients developing such toxic reactions have been included in a 'skin reaction' group. Leucopenia was defined as a white blood cell count 
below $3000 / \mathrm{mm}^{3}\left(3 \times 10^{9} / \mathrm{l}\right)$ while an upper limit of 100000 blood platelets $/ \mathrm{mm}^{3}\left(100 \times 10^{9} / \mathrm{l}\right)$ was given for thrombocytopenia. An increase of $100 \%$ or more of the enzymes alkaline phosphatases (ALP) and alanine aminotransferase (ALAT) or the development of jaundice was regarded as a liver reaction. A persistent positive urine reaction (Albu-stix) of ++ or more for protein was noted as proteinuria. Owing to the low number of patients the following adverse reactions were not analysed further with respect to HLA association; fever, itching, thrombocytopenia, haematuria, lymphadenopathy, severe pain after injections, and conjunctival inflammation.

HLA antigens. The HLA typing was performed by a microcytotoxicity technique with 87 highly selective antisera defining $13,21,4$, and 8 antigens of the $\mathrm{A}, \mathrm{B}$, $\mathrm{C}$, and DR series respectively by techniques previously described. ${ }^{9}$ Healthy controls included unrelated panel members, blood donors, and relatives of transplant patients previously typed at the Tissue Typing Laboratory (several thousands have been typed for the HLA ABC antigens, and 100-200 for the HLA DR antigens). ${ }^{10}$ Patients with the HLA antigens DR5, DRw6, and DRw8 were excluded from further analyses because of the low number of patients with these antigens.

Statistics. The chi-square test was used for statistical analysis, and a $\mathrm{p}$ value of less than 0.05 was considered to be statistically significant.

\section{Results}

Sixty-five per cent of the patients developed adverse reactions to gold. Skin reactions were most frequently observed $(42 \%)$, and proteinuria ( $11 \%)$ was the second most common toxic reaction (Table 1). Leucopenia and liver reactions were seen in $4.6 \%$ and $3.8 \%$ of the patients respectively. Other side effects accounted for $3.6 \%$.

As shown in Table 1, a high frequency of one or more side effects ( $94 \%$ ) was seen in the DR3 positive group, and these patients had significantly greater frequency of side effects than patients lacking this antigen and also than patients possessing DR7 or DR2. The relative risk for DR3 positives of developing gold toxicity was calculated to be 10 times that of DR3 negatives. The lowest frequencies of side effects were seen among DR7 and DR2 positives, $35 \%$ and $48 \%$ respectively. Cutaneous reactions, however, occurred with rather similar frequencies in all antigen groups except for DR7 positive patients, who had significantly fewer skin rashes than those without this antigen.

Proteinuria varying from $0 \cdot 1 \mathrm{~g} / 1$ to $2.9 \mathrm{~g} / \mathrm{l}$ developed significantly more often among patients positive for DR3 (44\%) than among patients negative for this antigen $(9 \%, p<0 \cdot 001)$ (Table 2). On the basis of our data we calculated that DR3 positives had 11 times greater chance of getting proteinuria than the DR3 negatives. The urinary protein was quantified in 11 of the 15 patients developing proteinuria. When the 4 patients in whom the proteinuria was not quantified were excluded from the material, the association between DR3 and proteinuria was still statistically significant. However, in only 3 of the 15 patients did the proteinuria exceed 2 $\mathrm{g} / \mathrm{l}$, and of these 3 patients only one carried HLA DR3. Only one patient out of 17 possessing DR7 developed proteinuria during gold therapy, and this patient also carried HLA DR3. It was also noted that

Table 1 Frequency (\%) of adverse reactions to gold and their association with certain HLA DR antigens

\begin{tabular}{lcccccc}
\hline & $\begin{array}{l}\text { No. of } \\
\text { patients }\end{array}$ & Rash & Proteinuria & $\begin{array}{l}\text { Liver } \\
\text { toxicity }\end{array}$ & $\begin{array}{c}\text { Leucopenia } \\
\text { One or more } \\
\text { side effects }\end{array}$ \\
\hline DR1 & 24 & 33 & 23 & 0 & 4 & 63 \\
DR2 & 25 & 39 & 8 & 4 & 0 & 48 \\
DR3 & 16 & 40 & 44 & 13 & 0 & 94 \\
DR4 & 79 & 46 & 6 & 0 & 6 & 66 \\
DR7 & 17 & 18 & 11 & $3 \cdot 8$ & $4 \cdot 6$ & 65 \\
Total & 132 & 42 & & & 0 & \\
\hline
\end{tabular}

Table 2 Frequency (\%) of HLA DR antigens in 132 RA patients with and without gold induced proteinuria

\begin{tabular}{lrccccccccc}
\hline & No. & $D R 1$ & $D R 2$ & $D R 3$ & $D R 4$ & $D R 5$ & DR6 & DR7 & DRw8 & $D R-$ \\
\hline Proteinuria & 15 & 23 & 8 & $44^{*}$ & $31^{* *}$ & 0 & 8 & 6 & 8 & 15 \\
No proteinuria & 117 & 24 & 18 & $8^{*}$ & $70^{* *}$ & 4 & 5 & 14 & 3 & 6 \\
\hline
\end{tabular}

${ }^{*} \mathrm{p}<0 \cdot 001 .{ }^{* *} \mathrm{p}<0 \cdot 05$. 
the frequency of DR4 was significantly higher among those patients who did not develop proteinuria than among the patients who developed it.

No significant differences between the antigen groups emerged with respect to liver reactions and leucopenia. But it was noteworthy that liver reactions and leucopenia were not seen among DR7 positive patients. No haematological complications occurred among patients with DR3.

There was no difference between the various antigen groups with respect to total dose of gold given before onset of adverse reactions

\section{Discussion}

The present retrospective study confirms previous reports $^{4-6}$ that RA patients carrying the HLA antigen DR3 seem to be at great risk of developing toxic reactions to gold. This was particularly true with respect to proteinuria, since 7 of the 15 patients developing this side effect carried HLA DR3, and since DR3 positives had a significantly greater tendency for developing proteinuria than patients lacking this antigen. The development of proteinuria, however, was not solely associated with the presence of this antigen.

Our results are in agreement with the work of Panayi et al. ${ }^{4-6}$ The relative risk of proteinuria associated with this type of medical treatment was calculated to be 32 times greater in patients with DR3. On the other hand Karr et al. ${ }^{11}$ could not confirm the impression that patients with DR2 or DR3 were more likely to have toxic reactions to gold or penicillamine than patients without these antigens. Likewise, in the 8th Histocompatibility Workshop ${ }^{12}$ no significant association between HLA antigens and allergic side effects to these drugs was reported.

The nature of the association between the presence of DR3 and the development of proteinuria in gold treated patients is not clear. We have shown (Gran J T, Husby G, Thorsby E, submitted for publication) that our DR3 positive RA patients had some disease features characteristic of systemic lupus erythematosus (SLE), particularly a high frequency of antibodies to nuclear antigens. Unlike most RA patients, SLE patients frequently have renal involvement, and they carry DR3 more frequently than normal controls. ${ }^{13} \mathrm{~A}$ possible explanation for the association between gold induced proteinuria and DR3 might lie at the receptor level, with an increased renal sensitivity in DR3 positives. These patients might also more easily produce autoantibodies directed against renal antigens or eventually immune complexes, which might localise in the kidneys and cause tissue damage. ${ }^{14}$

A low frequency of side effects to gold was found among DR2 positives in the present series, and this was in contrast to the previously reported greater tendency for these patients to develop toxic reactions to gold. ${ }^{4}$ Moreover patients with DR7 seemed to have some degree of protection against gold toxicity, which is in agreement with another report, ${ }^{7}$ and it was interesting that the only patient who developed proteinuria also possessed DR3. The negative correlation between presence of DR4 and drug induced proteinuria reported by others ${ }^{7}$ was also confirmed in the present study. Determination of HLA DR antigens prior to gold therapy might be helpful in detecting patients at special risk of developing gold toxicity, and our findings together with those of Panayiet al. . $^{4-6}$ point to the need to monitor urine specimens frequently during the gold treatment of RA patients with DR3. However, it is noteworthy that proteinuria, although significantly associated with HLA DR3, also developed in patients lacking this antigen, and that the severity of the proteinuria was not associated with any particular DR antigen in the present series. Furthermore, it was clear that at present tissue typing is of little use with respect to predicting which patients might develop side effects to gold other than proteinuria. Cutaneous reactions were the major problem in our patients, and no particular DR antigen was found to be associated with the skin rashes. The everyday clinical problem of selecting RA patients for gold therapy is therefore not satisfactorily solved by the introduction of typing for HLA DR antigens. It is also not known which patients will experience remission of RA during gold therapy, and prospective studies are needed to elucidate this question.

This work was supported by the Norwegian Research Councils for Science and the Humanities, the Norwegian Women's Health Association, and the Norwegian Rheumatism Council.

\section{References}

1 Forestier $\mathrm{H}$ J. L'aurothérapie dans les rheumatismes chroniques. Bull Mem Soc Med Paris 1929; 59: 323-7.

2 Lande K. Die günstige Beeinflussung schleichender Dauerinfekte durch Solganal. Munch Med Wochenschr 1927; 74: 1132-4.

3 Kirpilä J, Ripatti N. Complications of gold therapy in rheumatoid arthritis. Duodecim 1957; 10: 547-608.

4 Panayi G S, Wooley P, Batchelor J R. Genetic basis of rheumatoid disease: HLA-antigens, disease manifestations, and toxic reactions to drugs. $\mathrm{Br}$ Med J 1978; ii: 1326-8.

5 Wooley P M, Griffin J, Panayi G S, Batchelor J R, Welsh I C I, Gibson T J. HLA-DR antigens and toxic reactions to sodiumaurothiomalate and D-penicillamine in patients with rheumatoid arthritis. $N$ Engl J Med 1980; 303: 300-2.

6 Panayi G S, Griffin A J, Wooley P M. Genetic predisposition to gold and penicillamine toxicity. Arthritis Rheum 1979; 22: 645. 
7 Repice M M, Radvany R M, Schmid F R. HLA-A, -B, -C and -DR locus antigens and gold toxicity in rheumatoid arthritis. Clin Res 1979: 647A.

8 Ropes M W, Bennet G A, Cobb S, Jacox R, Jessar R A. Diagnostic criteria for rheumatoid arthritis: 1959 revision. Bull Rheum Dis 1958; 9: 175-6.

9 Albrechtsen D, Bratteli A, Nousiainen M, Thorsby E. Serological typing of HLA-D: predictive value in mixed lymphocyte cultures (MLC). Immunogenetics 1978; 6: 91-100.

10 Thorsby E. The human histocompatibility complex HLA: some recent developments. Transplant Proc 1979; 9: 616-23.
11 Karr R W, Rodey G E, Lee T, Schwark B D. Association of HLA-DRw4 with rheumatoid arthritis in black and white patients. Arthritis Rheum 1980; 23: 1241-5.

12 Stastny P. Joint report. Rheumatoid arthritis. In: Terasaki P I. Histocompatibility testing. Los Angeles: UCLA Tissue Typing Laboratory, 1980: 681-6.

13 Scherak H, Smolen J S, Mayr W R. HLA-DRw3 and systemic lupus erythematosus. Arthtitis Rheum 1980; 23: 954-7.

14 Tornroth T, Skrifvars B. Gold nephropathy, prototype of membraneous glomerulonephritis. Am J Pathol 1974; 75: 573-84. 